Geopolítica(s) Revista de estudios sobre espacio y poder ISSN: 2172-3958

\title{
Movilidad por salud entre Arica y Tacna: análisis de una demanda no satisfecha y de una oferta atractiva del otro lado de la frontera ${ }^{1}$
}

\author{
Nanette Liberona Concha ${ }^{2}$, Marcela Tapia Ladino ${ }^{3}$ y Yasna Contreras Gatica ${ }^{4}$
}

Recibido: 12 de mayo de 2017 / Aceptado: 13 de octubre de 2017

Resumen. En este artículo se abordan las razones que explican la movilidad por salud de los habitantes de Arica hacia la ciudad de Tacna basado en una metodología mixta (encuesta y entrevistas). Este movimiento corresponde a las personas que cruzan la frontera con fines médicos, tanto para atenderse en servicios de salud peruanos como para comprar medicamentos, lentes u otros en la ciudad de Tacna. Se parte del supuesto que dichos cruces ocurren con independencia de los litigios fronterizos y están motivados por la mercantilización y deficiencias del sistema chileno de salud pública y por una oferta tacneña más económica, de mejor trato y de acceso rápido a especialistas y exámenes médicos. Sin embargo, la movilidad por salud responde a controles rutinarios, chequeos médicos o de segunda opinión y en menor medida a procedimientos médicos de mayor complejidad debido a la inexistencia de cobertura por seguros, desconocimiento y en algunos casos, desconfianza por los resultados.

Palabras clave: frontera; movilidad; salud; Chile; Perú.

\section{[en] Health Mobility between Arica and Tacna: Analyzing an Unsatisfied Demand and an Attractive Offer across the Border}

\footnotetext{
Abstract. Adopting a mixed-methods approach (surveys and interviews), this article addresses the phenomenon of health mobility from Arica to Tacna. It shows that Arica's inhabitants cross the border to the city of Tacna for purposes such as using the Peruvian health services, purchasing medicines, glasses and other commodities. The argument is that irrespective of border disputes, bordercrossing takes place as a result of the increasing commoditization and low quality of Chile's public health system. Tacna, instead, offers affordable and generally better services, with quick access to specialists and medical examinations. Yet, while routine controls, health checks and second-opinion visits motivate border-crossing in large measure, complex medical procedures feature less prominent-

1 Este artículo es resultado del Proyecto FONDECYT Regular $N^{\circ} 1150123$ "Cruzar y vivir en la frontera de Arica y Tacna. Movilidad y circulación 1990-2010”. Queremos agradecer al equipo de investigación que colaboró en esta investigación, en especial las ayudantes de investigación Damary Vilca, Fernanda Chacón, Isidora Palma, Angélica Barra y Valentina Salles. Asimismo, a quienes participaron en calidad de encuestados y entrevistados (informantes claves y cruzadores) y a las entidades que nos abrieron sus puertas para obtener información entre ellas Municipalidad de Arica y de Tacna y el Hospital de la Solidaridad de Tacna.

2 Instituto de Estudios Internacionales - INTE, Universidad Arturo Prat, Chile.

E-mail: nalibero@unap.c1

3 Instituto de Estudios Internacionales - INTE, Universidad Arturo Prat, Chile.

E-mail: marcelatapial@gmail.com

4 Departamento de Geografía, Universidad de Chile, Chile.

E-mail: ycontrerasg@uchilefau.cl
} 
ly in the study especially due to lack of insurances, lack of information and, in some cases, distrust on the results.

Keywords: border; mobility; healthcare; Chile; Peru.

\section{[pt] Mobilidade por saúde entre Arica e Tacna: Análise de uma demanda não satisfeita e de uma oferta atrativa do outro lado da fronteira}

Resumo. Neste artigo são abordadas as razões que explicam a mobilidade por saúde dos habitantes de Arica em direção à cidade de Tacna, baseando-se em metodologia mista (enquete e entrevistas). Este movimento corresponde às pessoas que cruzam a fronteira com fins médicos, tanto para serem atendidas em serviços de saúde peruanos, quanto para comprar medicamentos, lentes ou outros na cidade de Tacna. Parte-se do pressuposto que que tais cruzamentos ocorrem independentemente dos litígios fronteiriços e são motivados pela mercantilização e pelas deficiências do sistema chileno de saúde pública, mas também por uma oferta em Tacna que é mais econômica, de melhor tratamento e de acesso rápido a especialistas e exames médicos. No entanto, a mobilidade por saúde responde a controles de rotina, exames médicos ou de segunda opinião e em menor medida a procedimentos médicos de maior complexidade devido à inexistência de cobertura por planos de saúde, desconhecimento e em alguns casos, por desconfiança em relação aos resultados.

Palavras-chave: fronteira; mobilidade; saúde; Chile; Peru.

Sumario. Introducción. 1. Metodología para el estudio de la movilidad por salud entre Arica y Tacna. 2. Frontera, prácticas socioespaciales fronterizas y movilidad por salud. 3. Sistema de salud chileno y oferta médica como parte de la atracción tacneña. 4. Movilidad por salud hacia Tacna como respuesta de una demanda insatisfecha en Arica. 5. El acceso a especialista, economía y rapidez en la atención de salud tacneña. 6. Calidad y confianza de la atención médica tacneña en un contexto separador de la frontera. Conclusiones. Bibliografía.

Cómo citar: Liberona Concha, Nanette; Tapia Ladino, Marcela \& Contreras Gatica, Yasna (2017) "Movilidad por salud entre Arica y Tacna: análisis de una demanda no satisfecha y de una oferta atractiva del otro lado de la frontera". Geopolítica(s). Revista de estudios sobre espacio y poder, vol. 8, núm. 2, 253-278.

\section{Introducción}

El número de cruces de la frontera que separa Arica de Tacna ha experimentado un rápido crecimiento en las últimas décadas. Desde el año 2000 - fecha a partir de la cual se cuenta con datos periódicos- se contabilizaron más de 1.165 .000 cruces (entradas y salidas) por el paso fronterizo de Chacalluta (Ver Figura 1). El año 2008 las cifras superaron los 4 millones y para el 2014 se produjo un aumento en los cruces llegando a 5.687.000. A finales del 2016 se contabilizaron más de 6 millones de cruces anuales ${ }^{5}$. De ese total algunos siguen otros destinos al interior de Chile o Perú, otros en cambio cruzan sólo por unos días y otros se movilizan durante el día. De manera específica, y según datos de la Municipalidad de Tacna se estima que más del $70 \%$ de los cruces corresponden a residentes de Arica que atraviesan la frontera hacia Tacna en calidad de "visitantes extranjeros", es decir, personas que residen en Arica y que viajan a Tacna por el día (Gárate, 2016). Los

5 Información obtenida de la Sección de Acceso de Información Pública de la Policía de Investigación por la Ley de Transparencia N²0.285 con fecha 29de septiembre de 2015. 
cruces tienen diversos fines y varían de un sentido a otro. Los chilenos residentes en Arica que cruzan a Tacna lo hacen fundamentalmente por motivos de salud, ocio, compras y comercio, y los peruanos residentes en Tacna que cruzan a Arica tienen prácticas transfronterizas vinculadas al comercio, así como también trabajos agrícolas en los valles de Azapa y Lluta (Tapia Ladino, Liberona Concha \& Contreras Gatica, 2017).

Figura 1. Límite y distancia entre Arica (Chile) y Tacna (Perú)

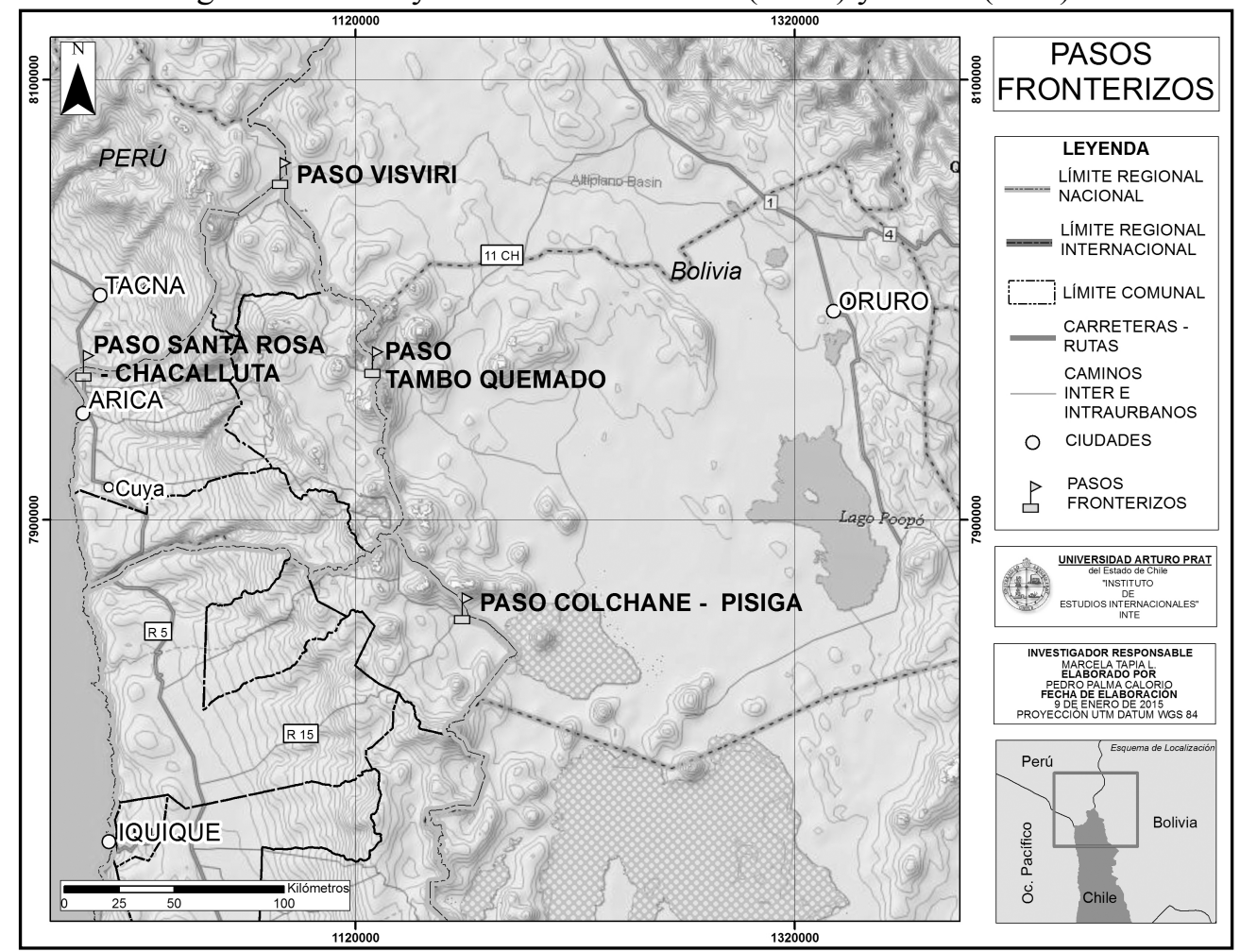

Fuente: Mapa realizado por Rodrigo González para el Fondecyt 1150123.

La distancia que separa Arica de Tacna es de casi $60 \mathrm{~km}$ y el cruce de la frontera supone una hora y media de viaje, situación que mejoró desde agosto de 2017 por la instalación del control integrado en Chacalluta (Chile) y Santa Rosa (Perú) La rapidez y la cercanía es una condición que produce cotidianidad entre quienes cruzan (Figura 1). No obstante, existe escasa preocupación por estos movimientos en las Ciencias Sociales chilenas puesto que los estudios se han centrado fundamentalmente en la inmigración de peruanos al país. En este contexto este artículo

6 Desde el 16 de agosto de 2017 entró en vigor el control integrado en el paso fronterizo de Chacalluta (Chile) y Santa Rosa (Perú). Esta modalidad consiste en una detención al momento del cruce para control de documentos y mercancías lo que implica simplificación y agilización de los trámites. Se trata de un compromiso adquirido por las cancillerías de Chile y Perú que busca agilizar los controles fronterizos y optimizar la atención a los usuarios. Ver URL: <http://www.pasosfronterizos.gov.cl/n1256_16-08-2017.html>. Consultado el 12 de diciembre de 2017. 
se propone indagar por las características y razones de un tipo de movilidad transfronteriza que se produce entre Arica y Tacna: la movilidad por salud. La pregunta que guía este trabajo es: ¿Cuáles son las razones que explican la movilidad transfronteriza de ariqueños hacia Tacna en su búsqueda por resolver problemas de salud? La hipótesis postula que la movilidad por salud de los residentes de Arica que se atienden en Tacna responde a una demanda no satisfecha del sistema de salud chileno y a una oferta de salud atractiva que es independiente de los litigios y las demandas jurídicas existentes en torno a la frontera chileno-peruana. La Figura 1 evidencia las condiciones geográficas del cruce Santa Rosa-Chacalluta, así como la localización de las dos ciudades de estudio.

A partir del tránsito que han experimentado los estudios fronterizos desde la concepción de la frontera como una línea o demarcación se establecen nuevos enfoques en las Ciencias Sociales develando el sentido de las interacciones que ocurren en las fronteras. Diferentes autores (Newman, 2015; Trillo \& Lois, 2011; Zapata-Barrero \& Ferrer-Gallardo, 2012) investigan sobre los vínculos y movilidades que despliegan los habitantes de zonas fronterizas. En general estos estudios advierten de las nuevas connotaciones que adquiere la frontera más allá de los conflictos fronterizos o internacionales en el marco de la globalización y de los factores históricos poscoloniales que configuraron las fronteras actuales (Banerjee \& Chen, 2013).

Después del optimismo de la caída del Muro de Berlín (1989) y la expansión de la idea de un "mundo sin fronteras" se ha pasado a un rebrote de la construcción de nuevos muros (28 terminados o planeados), especialmente después de los atentados del 11/S en Nueva York (Tripathi, 2015). Últimamente, estudios en la Unión Europea (UE) verifican que hay un aumento de la movilidad dentro del espacio Schengen, especialmente de europeos orientales a Europa occidental. El aumento de la conectividad, las redes y la movilidad humana al interior de la Unión Europea da lugar a lo que Marcu (2016: 16) denomina una "liberación transfronteriza" que está reconfigurando al continente en clara contradicción con el reforzamiento de la frontera externa. Esto último devela que las fronteras y las regiones colindantes o fronterizas no son estáticas sino dinámicas en su desarrollo y están afectadas por distintas fuerzas de nivel global, nacional y local que actúan en diferentes direcciones y escalas.

Los movimientos de población que interesa revisar en este artículo son aquellos que quedan fuera de la noción de migración porque ésta contiene en su definición el establecimiento en el lugar de destino y un carácter bidireccional (origen y destino) en clave nacional. En este caso el concepto movilidad es más preciso para la comprensión de los movimientos que ocurren en una región fronteriza ya que en primer lugar no implican un cambio de residencia $y$, en segundo lugar, porque el movimiento se define respecto del lugar de origen, el tiempo del cruce y los motivos (Castillo \& Nájera, 2014). Así la movilidad alude fundamentalmente a movimientos de corta duración, uno o varios días o semanas, que no suponen el establecimiento en el otro sitio, implican una periodicidad, cruces constantes o también esporádicos (Castillo \& Nájera, 2014).

La frontera chileno-peruana ha sido motivo de numerosos litigios desde la segunda mitad del siglo XX a la fecha (González, 2004; González, 2007; González, 2011), por tanto, es posible afirmar que se trata de una frontera demandada, especialmente por parte del Gobierno peruano (Rodríguez Elizondo, 2014). Sin embar- 
go, los habitantes de las ciudades fronterizas han desplegado una serie de prácticas transfronterizas cotidianas con fines laborales, comerciales, de compras, ocio y salud (Tapia Ladino, Liberona Concha \& Contreras Gatica, 2017). Estas prácticas construyen una territorialización en torno a la frontera, propiciando el surgimiento de un territorio circulatorio (Tarrius, 2000; Tarrius, 2007) que asume los espacios como soportes para la movilidad, rompiendo de esta forma con el paradigma de sedentarización (Tarrius, 2010: 139). En un sentido similar los aportes de Sheller \& Urry sobre el paradigma de las "nuevas movilidades" (Sheller \& Urry, 2006) discuten la noción de sedentarismo o establecimiento que ha predominado en las ciencias sociales en general. Los autores consideran que el impacto que los viajes, el transporte y las comunicaciones, como nuevas y complejas experiencias de las personas, son las que ponen a prueba la idea de normalidad del lugar y del establecimiento y como anormal el cambio y el movimiento (Sheller \& Urry, 2006).

Por otra parte, la relación entre salud y movilidad humana en América del Sur se ha enfocado en el acceso y uso de servicios de salud desde la perspectiva de la inmigración. En Argentina colocan en el centro del debate la escasez de recursos y los mecanismos de distribución, así como, también, si deben o no tener prioridad quienes residen en el país o en áreas específicas (Jelin \& Grimson, 2005). Es así como los derechos de los y las extranjeras son puestos en discusión en relación con los derechos de acceso a la salud de los/as ciudadanos/as locales o nativos/as (Liberona, 2012; Waldman, 2011).

En cuanto a quiénes tienen derecho de acceso a la salud, Courtis, Liguori \& Cerrutti (2010) analizando la frontera argentino-boliviana sostiene que existen diversos tipo de movilidad: "en la actualidad, se registra en la zona - postergada socioeconómica y políticamente - una amplia gama de situaciones migratorias y de movilidad que incluyen la residencia habitual, la migración laboral temporaria para la zafra, la migración laboral fronteriza, los movimientos de los abastecedores (paseros/as y vendedores/as ambulantes) y consumidores fronterizos, el tránsito hacia otros destinos en el país y la movilidad indígena" (Courtis, Liguori \& Cerrutti, 2010: 7), sin embargo, la autora no profundiza en la movilidad por motivos de salud.

En este contexto se aprecia que los temas de salud en la frontera han sido escasamente estudiados, prestando atención más bien al "control sanitario fronterizo antes que al derecho a la salud de la población migrante" (Courtis, Liguori \& Cerrutti, 2010: 8). Por su parte, Brasil ha vivido una fuerte demanda en cuestiones de salud en las regiones fronterizas con Argentina, Paraguay y Uruguay, debido a los acuerdos de libre tránsito de personas entre los Estados partes del MERCOSUR, que ha permitido la libre circulación de personas ${ }^{7}$. Estos acuerdos facilitan la residencia y permiten ejercer el derecho a la salud de los extranjeros de países vecinos en Brasil como país receptor (Coelho, 2012; Dal Prá, Mendes \& Mioto, 2007). Se concluye, por tanto, que los movimientos de población en las fronteras develan una mayor circulación de personas debido a las asimetrías entre los sistemas de salud

\footnotetext{
A nivel del proceso de integración regional Mercado Común del Sur MERCOSUR, los acuerdos de libre tránsito de personas entre los Estados partes y Estados asociados han permitido que las personas que circulan de un Estado a otro no tengan la necesidad de cumplir con requisitos generales del marco jurídico en materia migratoria, facilitando su residencia, lo que les permite ejercer su derecho a la salud en los Estados receptores (Courtis, Liguori \& Cerrutti, 2010).
} 
de los distintos Estados, lo que las hace más propensas a ser escenario de tensiones sanitarias (Abel \& Caggiano, 2006; Cerruti, 2006). Por último, las fronteras latinoamericanas, en general son regiones postergadas y alejadas de las respectivas capitales nacionales (Caggiano, 2007), lo que repercute en los sistemas de seguridad social y previsión social.

\section{Metodología para el estudio de la movilidad por salud entre Arica y Tacna}

Para el estudio de las prácticas sociales fronterizas y, en particular, de la movilidad por salud se trianguló la información resultante de una encuesta, de entrevistas y de observación. Primero, se aplicó una encuesta de movilidad durante el mes de julio del 2015 en la que fueron encuestadas 240 personas residentes de Arica y/o Tacna que tenían como destino al momento del cruce una de esas ciudades. El instrumento se aplicó en el paso fronterizo de Chacalluta (Chile). El cuestionario contempló 54 preguntas, las cuales se iban acotando según los motivos del cruce (laboral, turismo, compras, comercio y ocio). Considerando el motivo del cruce los encuestados respondían una parte del cuestionario en consideración al perfil de movilidad, habiendo preestablecido los perfiles: migrante, trabajador, comerciante y turista. El instrumento consideró a personas mayores de 18 años residentes de Arica y Tacna y que tuvieran por destino a una de esas ciudades. La encuesta fue aplicada a "individuos" y no a grupos familiares. La encuesta fue aplicada por nuestro equipo en la salida y el ingreso a Chile, en distintas franjas horarias con el fin de captar la variedad de cruces (mañana, mediodía y noche). El universo encuestado (240) estuvo compuesto por 147 peruanos, 91 chilenos, 1 ecuatoriano y 1 boliviana de los cuales 121 son hombres y 119 mujeres. Del total se captaron 153 ingresos a Chile y 87 salidas del país.

En segundo lugar, se entrevistaron a 27 informantes claves y a 11 cruzadores que declararon prácticas espaciales transfronterizas por motivos de salud. Los entrevistados claves comprendieron a personas vinculadas al área de la salud tanto en Arica como en Tacna, así como también a instituciones del gobierno local, regional o central quienes entregaron información histórica y de contexto respecto a las prácticas de salud en el paso fronterizo. Las entrevistas fueron realizadas en los lugares de trabajo o domicilio de los informantes clave y en la sala de espera del Hospital de la Solidaridad, así como en la fila de espera del paso fronterizo de Chacalluta, en la salida de Chile y en dos restaurantes. En tercer lugar, se llevó a cabo un trabajo etnográfico de movilidad transfronteriza, la observación facilitó la comprensión de las prácticas espaciales, el reconocimiento de lugares frecuentados por los encuestados y entrevistados, así como también las limitantes o posibilidades del cruce.

El artículo se organiza de la siguiente forma, en la primera parte se revisa la producción teórica sobre frontera, movilidad y salud, especialmente a la luz de la producción de los "estudios fronterizos" (border studies) y de las investigaciones que han ahondado en la investigación sobre turismo médico. En segundo lugar, se revisó la historia del sistema de salud chileno y del desarrollo de la oferta de salud en Tacna a partir de fuentes secundarias y entrevistas a informantes claves. La tercera parte se aboca al análisis de las entrevistas a cruzadores que se atienden en el sistema de salud tacneño y las valoraciones que hacen de dicha oferta. La cuarta 
parte indaga acerca de la confianza y el riesgo percibido por quienes se atienden en Tacna y de las posibilidades de optar a procedimientos más complejos teniendo en cuenta la apreciación de los entrevistados sobre los litigios en torno a la frontera chileno-peruana.

\section{Frontera, prácticas socioespaciales fronterizas y movilidad por salud}

Para comprender las prácticas sociales fronterizas, y en particular la movilidad por salud en una región fronteriza es preciso conocer el debate reciente sobre fronteras, prácticas fronterizas y el turismo de salud como marco de referencia. Respecto de los dos primeros, existe un amplio corpus desarrollado en los estudios fronterizos que advierten de los cambios en los significados y sentidos de las fronteras nacionales en el contexto de la globalización (Brambilla, 2015) así como del surgimiento de una serie de dinámicas en torno a las fronteras que hasta hace poco no eran el foco de la atención de las Ciencias Sociales (Zapata-Barrero \& Ferrer-Gallardo, 2012).

Lo que se verifica en la actualidad es que las regiones fronterizas se caracterizan por la existencia de una variedad de dinámicas e interacciones que en muchas ocasiones son anteriores al establecimiento de los actuales límites (Amilhat Szary \& Rouvière, 2011; Eilenberg \& Wadley, 2009) y se han intensificado en los últimos tiempos. En este contexto, el desarrollo más reciente de los estudios fronterizos se centra en los movimientos de los habitantes en torno y a través de las fronteras, los motivos y tiempos de los cruces y las interacciones en los espacios fronterizos. Estos estudios se detienen en las prácticas socio-espaciales fronterizas (Tapia Ladino, Liberona Concha \& Contreras Gatica, 2017) o prácticas fronterizas (Aguilar \& Costilla, 2009: 57-58; Morales, 2010; Parella, 2014) cuyo objetivo es aprovechar las ventajas del cruce o las oportunidades que ofrece pasar al otro lado.

En varias partes del mundo las delimitaciones poscoloniales o decimonónicas separaron comunidades (Tripathi, 2015) lo que se ha constituido en un obstáculo para la interacción, pero no el término de la misma (Banerjee \& Chen, 2013). Así, las regiones fronterizas, a diferencia de otras regiones dentro de un mismo Estadonación, se caracterizan por estar más afectadas por la influencia de la vecindad y porque la frontera expresa las diferencias y las asimetrías entre dos o más espacios colindantes (Morales, 2010). Las desigualdades dadas por las brechas de desarrollo, los distintos regímenes legales sobre migración, ingreso y tránsito, así como por las diferentes ofertas de servicio a uno y otro lado del linde, favorecen e incentivan el cruce (Aponte, 2012; Hui et al., 2011; Steiman, 2012). De modo que las desigualdades que se expresan en las fronteras se traducen en diferencias salariales, en el costo de la vida, en el acceso a servicios y en distintos tipos de beneficios económicos. Como señala Benedetti (2011: 58), estas diferencias que se expresan en la frontera explican la hipótesis del cruce.

Los estudios fronterizos recientes dan cuenta de estas interacciones en distintas latitudes a pesar del resurgimiento de los muros, el rebrote de conflictos fronterizos o de la creación de nuevas fronteras, invisibles, formales o informales (Tripathi, 2015: 4). Conocidos son los estudios en la frontera entre México y Estados Unidos que muestran la migración hacia el país del norte. No obstante, últimamente las investigaciones prestan atención a las prácticas fronterizas entre habitantes de ciuda- 
des colindantes, como entre Mexicali y Caléxico o Tijuana y San Diego, donde las personas cruzan diaria o semanalmente para estudiar, trabajar o comprar en uno y otro lado de la frontera (Parella, 2014). De manera similar ocurre entre Estados Unidos y Canadá donde los habitantes fronterizos aprovechan las diferencias del cambio para hacer compras al otro lado (Konrad \& Nicol, 2011). En la frontera entre México con Guatemala y Belice las investigaciones se focalizan específicamente en el estado de Chiapas, principal receptor de mano de obra temporal centroamericano (Rojas et al., 2008). En América del Sur existen casos similares entre Leticia y Tabatinga o Encarnación y Misiones, donde los habitantes de las localidades fronterizas aprovechan las diferencias salariales y económicas para abaratar el costo de la vida, trabajar, comerciar o acceder a actividades de ocio a las que no tienen acceso en sus países (Aponte, 2012; Jaquet, 2008).

En China y la India, donde la configuración de las fronteras se remonta a la colonización y descolonización británica, las comunidades fronterizas coexisten pacíficamente más allá de las dificultades de la geografía y los litigios fronterizos. El cruce de las fronteras se explica por la pobreza y las necesidades de los residentes, especialmente en lo referido a atención médica, oferta de trabajo o posibilidades para comercializar mercancías (Banerjee \& Chen, 2013). De manera similar ocurre en otros puntos de Asia, como entre Malasia y Borneo, donde un grupo étnico, los iban, distribuidos a uno y otro lado de la frontera cruzan hacia Malasia usando los vínculos étnicos para trabajar y aprovechar las ventajas económicas del país (Eilenberg \& Wadley, 2009). Así, los estudios demuestran cómo en distintas partes del mundo las fronteras expresan las asimetrías, que se convierten en un recurso y en un capital de movilidad para los habitantes de las regiones fronterizas.

Respecto del segundo punto señalado, los estudios que vinculan salud y turismo vienen dando cuenta de una serie de movimientos a través de las fronteras cuyo propósito es fundamentalmente médico, pero no exclusivamente. La noción de turismo médico, que se ha venido usando para aludir a los viajes transfronterizos que buscan recibir atención médica en un país distinto al de origen, es hoy motivo de discusión. El debate se ubica en un doble sentido, en primer lugar, se cuestiona el aspecto turístico - en tanto que fuente de relajo y placer - contenido en estos viajes, ya que muchas veces las personas cruzan las fronteras buscando ayuda sanitaria o tratamientos de manera desesperada y frustradas por no encontrar alternativas en sus países (Connell, 2015: 399). En otro sentido, se cuestionan los tipos de atenciones y tratamientos que buscan las personas al cruzar las fronteras, puesto que no se trata sólo de personas ricas que necesitan someterse a procedimientos estéticos o acceder a tratamientos prohibidos en sus países como cambios de sexo, vientres de alquiler o aborto en lo que se ha llamado "turismo de elusión" (Connell, 2015: 399).

Lo que advierten los estudios recientes es que muchas personas realizan viajes cortos, fronterizos o transfronterizos de distancia media para acceder a servicios de salud porque están marginadas por la economía, la distancia y la cultura en su país de origen (Ormond \& Sulianti, 2014). Muchos viajeros cruzan las fronteras de África Sub-sahariana para ser atendidos en los hospitales de Sudáfrica, los de Laos cruzan a Birmania, o los indonesios pasan a Singapur y Malasia (Connell, 2016), los mexicanos residentes en Estados Unidos cruzan a México (Parella, 2014) o los bolivianos cruzan a Chile o Argentina para ser atendidos en los servicios de salud de esos países (Vindrola-Padros, 2015). Desde Chile se cruza a la ciudad de Neu- 
quén (Argentina) donde los agentes de salud del Hospital Central estiman que un $30 \%$ del total de pacientes que se atiende regularmente en el hospital es de origen chileno. También estiman que, dentro de este porcentaje, una proporción importante de pacientes chilenos reside en Chile y cruza la frontera únicamente para atenderse (Mombello, 2006: 91).

Por tanto, la evidencia muestra que más que turismo médico lo que existe son "viajes médicos" (Connell, 2015), "movilidad transfronteriza de pacientes" (Legido-Quigley et al., 2012), "movilidad de los pacientes" (Glinos et al., 2010) o "movilidad por salud", como se postula en este trabajo (Tapia Ladino, Liberona Concha $\&$ Contreras Gatica, 2017). Estos viajes han experimentado un aumento en los últimos 20 años, siendo en su mayoría Sur-Sur, informales, fronterizos y alejados de la noción de placer propia del turismo (Connell, 2016). Si bien es difícil cuantificar estos movimientos porque las personas no declaran los motivos al cruzar las fronteras, ya que normalmente lo hacen como turistas, indocumentados o clandestinos, los estudios muestran un aumento de estos viajes ante una demanda insatisfecha o no cubierta por los sistemas de salud nacionales (Ormond, 2015: 306). En un contexto de privatización de los sistemas sanitarios en distintas latitudes, baja cobertura social y mercantilización de la salud cada vez más las personas están dispuestas a cruzar las fronteras para acceder a servicios que no obtienen en sus países o para sortear las largas listas de espera para procedimientos que no son prioritarios (Glinos et al., 2010).

Por tanto, el vínculo entre frontera, movilidad y salud es aún un aspecto poco explorado en los estudios fronterizos que dan cuenta, por una parte, del crecimiento de una industria de salud privatizada, competitiva y orientada al consumidor y por otra, del aumento de la búsqueda de salud intrarregional entre países vecinos con diferencias de desarrollo, de tipos de atención, y desiguales niveles de acceso a tratamientos (Crush \& Chikanda, 2015). De modo que estas movilidades abarcan desde viajes para tratamientos estéticos, como los de "bisturí y safari" de Sudáfrica (Crush \& Chikanda, 2015) que aprovechan las brechas de desarrollo para acceder a tratamientos más económicos, hasta viajes de corta distancia para tratamientos menos complejos o de acceso restringido para pacientes pobres, que no poseen cobertura sanitaria o, si la tienen, se sienten insatisfechos con los sistemas de salud nacionales (Connell, 2015; Ormond, 2015; Pan \& Chen, 2014). En todos los casos el cruce de las fronteras se traduce en una oportunidad o en un recurso para acceder a una atención médica más económica, rápida y en muchos casos oportuna, por tanto, es un capital de movilidad.

\section{Sistema de salud chileno y oferta médica como parte de la atracción tacneña}

Para comprender el origen de la oferta tacneña relacionada con la salud y la movilidad por salud de los ariqueños, es preciso revisar brevemente la historia del sistema de salud chileno y la implantación de un modelo privatizador y mercantil de salud. En 1979 un decreto del Régimen Militar reorganizó el Sistema Nacional de Salud (SNS) y se descentralizaron los servicios de salud, estableciéndose las bases del actual Sistema Nacional de Servicios de Salud (SNSS) de Chile. Así, el financiamiento de la biomedicina y de los servicios de salud pasó a manos del Fondo Nacional de Salud (Fonasa). 
En 1980 se traspasaron los centros de salud primaria (CES) a las municipalidades y en 1981 se crearon las Instituciones de Salud Previsional (ISAPRES) con el fin de ofrecer prestaciones de salud privadas. Se estableció que todas las personas debían cotizar $7 \%$ de su salario imponible ${ }^{8}$. Así se estableció un sistema mixto de salud compuesto de dos sub-sistemas: el público y el privado, operando con grandes desigualdades entre ellos, así como al interior de cada uno de ellos, aunque de forma más marcada en el privado. En las ISAPRES, la protección a la cual accede el asegurado varía según el monto de la cotización y de los riesgos médicos asociados a cada persona, en función de la edad y del sexo del asegurado y de su grupo familiar (beneficiarios).

Los planes de salud de las ISAPRES tienen un costo total que puede ser modificado unilateralmente por éstas, sobrepasando el $7 \%$ obligatorio, lo que devela la mercantilización de la salud. Situación contraria sucede con el Fondo Nacional de Salud (FONASA), administrado por el Estado chileno, cuyo aporte único de 7\%, genera y ofrece un plan universal a todos sus beneficiarios, que comprenden el $78,29 \%$ de la población en Chile ${ }^{9}$. La atención en salud privada alcanza un $14,23 \%$ de la población ${ }^{10}$, y corresponde a las/los usuarios de ISAPRES y a quienes optan por la Modalidad de Libre Elección del profesional, en la cual el Estado (FONASA) subvenciona parcialmente el servicio de salud, permitiendo el desarrollo de una verdadera mercantilización de la salud o de una empresarialización de ésta. "Esta situación origina que ambas lógicas de provisión deban competir por profesionales y técnicos claves para proveer salud a sus usuarias(os)", tal y como se afirma en un documento del Ministerio de Desarrollo Socia ${ }^{11}$. Goyenechea \& Sinclair (2013) plantean que la privatización de la salud en Chile ha generado una injusta distribución de los recursos del Estado, provocando el desmantelamiento de la salud pública sin lograr atender las demandas de la población.

Por otra parte, si bien las reformas realizadas a partir del 2000 (Ley de Autoridad Sanitaria y de Gestión, Ley del Régimen General de Garantías en Salud o Ley de Acceso Universal a Garantías Explícitas de Salud o Plan AUGE) han generado logros en salud ${ }^{12}$, en lugar de resolver los problemas estructurales, continúan con esta lógica mercantilista. Valdivieso \& Montero (2010) analizan estas garantías y afirman que la especulación de la industria farmacéutica y el excesivo uso de exámenes, medicamentos y otros procedimientos de salud, están generando en Chile y en el mundo una inflación desmedida del costo de la atención y en el acceso a ésta para los grupos de menores ingresos. En el caso del AUGE al no existir una adecuada preparación de la red pública, el Estado subvenciona en muchos casos la salud privada para cubrir la demanda de las enfermedades que cubre el AUGE. Esto influye en el sistema de trabajo, ya que el libre mercado de salud permite a los pro-

Decreto Ley Nº. 2.763, de 1979, Ministerio de Salud; Subsecretaría de Salud Pública.

9 En URL: <http://observatorio.ministeriodesarrollosocial.gob.cl/documentos/Casen2013_Salud.pdf>. Consultado el 12 de septiembre de 2016.

10 En URL: <http://observatorio.ministeriodesarrollosocial.gob.cl/documentos/Casen2013_Salud.pdf>. Consultado el 12 de septiembre de 2016.

11 En URL: <http://observatorio.ministeriodesarrollosocial.gob.cl/documentos/Casen2013_Salud.pdf>. Consultado el 12 de septiembre de 2016.

12 A la fecha son 80 las patologías GES, es decir, las que cubre la "ley AUGE". Ver más en URL: $<$ http://www.gob.cl/10-anos-del-auge-los-logros-garantiasy-como-funciona-el-plan-de-salud/>. Consultado el 18 de octubre de 2016 . 
fesionales optar por el sector privado donde son mejor remunerados. Así, el sector público tiene menos profesionales, y menos especialistas de los que necesita. La falta de personal ha sido la principal evidencia de este problema, en especial en el nivel primario de salud (APS), es decir, en la puerta de entrada de los beneficiarios del sistema público de salud. En los APS hay un déficit de médicos y un alto nivel de rotación de profesionales, a causa de la poca motivación de parte de las instituciones hacia ellos ${ }^{13}$.

Otro déficit significativo se evidencia al analizar las tasas de médicos por habitantes, así como de graduados de medicina por habitante, al compararlas con las de países de la Organización para la Cooperación y Desarrollo Económicos (OCDE). Según datos de la Dirección de Presupuesto del Ministerio de Hacienda "de acuerdo a las estadísticas de salud del año 2015 generadas por la OCDE, nuestro país presenta una tasa de médicos de 1,9 por 1.000 habitantes, en tanto la media de los países de la OCDE es de 3,3 por 1.000 habitantes. En el mismo sentido, la tasa de graduados en Medicina es de 5,9 por 1.000 habitantes, en tanto la media de los países de la OCDE es de 11,2 por 1.000 habitantes"14.

A pesar de que se ha superado la precaria situación de los años 1990, en cuanto al estado de los establecimientos de la red hospitalaria, a la insuficiencia de camas, de equipos, de utensilios y de personal, el gasto público en el sector sigue siendo deficiente ${ }^{15}$. A esto se suma, la importancia del llamado "gasto de bolsillo" (Cid \& Prieto, 2011) es una característica del sistema de salud chileno es decir el gasto privado o particular que representa la principal fuente de participación en el financiamiento de la salud en Chile llegó a un 33\% en 2013 (MINSAL, 2016: 51). Según Cid \& Prieto (2011), el principal problema que esto genera es un impacto en la distribución de los ingresos en el país, calificando este financiamiento como "proricos" porque el que el Sistema de Seguridad Social en Salud en Chile, compuesto por FONASA y las ISAPRES, es un "arreglo institucional y financiero híbrido [que] ha generado grandes desigualdades en el acceso a la salud y en su calidad, que han redundado finalmente en la mantención o el aumento de las desigualdades en los niveles de salud de la población" (Cid \& Prieto, 2011: 1). Aravena \& Inostroza (2015: 1), mediante un estudio de opinión pública, concluyen que una mejor asignación de recursos, una atención oportuna en los servicios de urgencia y una disminución de los montos de copago mejorarían la satisfacción de los usuarios.

Respecto a los medicamentos, la Constitución Política chilena prohíbe al Estado regular el precio de éstos, lo que ha permitido el surgimiento de un mercado de las farmacias que con el tiempo se ha vuelto monopólico, promoviendo la colusión de los precios y costos excesivos ${ }^{16}$. En este contexto, aparecen las farmacias o drogue-

13 Mayor información disponible en URL: <https://www.medicosaps.cl/copia-de-noticia-20170103-1> y en URL: $\quad<\mathrm{http}$ //www.latercera.com/noticia/medicos-de-atencion-primaria-advierten-paralizar-sus-funciones-apartir-del-proximo-lunes/. Consultadas el 19 de agosto de 2016.

14 Ver URL: <http://www.elmostrador.cl/noticias/opinion/2015/12/22/la-salud-en-chile-una-crisis-estructural/>. Consultado el 20 de septiembre de 2016.

15 Se ha señalado que "aunque el financiamiento de la salud en Chile como porcentaje del PIB ha crecido en los últimos años alcanzando el 8,3\% en 2009 (OMS, 2011), nuestro país se encuentra en el grupo de naciones con menor gasto en salud de los miembros de la OECD, con una composición público-privada muy distinta al resto de los países debido a una predominancia del gasto privado por sobre el público" (Cid \& Prieto, 2011: 2).

16 Ver URL: <http://ciperchile.cl/2015/03/23/ley-de-farmacos-por-que-suben-los-precios-y-desaparecenproductos/>. Consultado el 12 de septiembre de 2016. 
rías populares como una forma de paliar los problemas de asequibilidad de los medicamentos, ya que permitirían el ahorro de hasta un $95 \%$ del costo del mercado ${ }^{17}$.

Finalmente, otro problema de desigualdad en el acceso a la salud chilena es la cobertura en salud dental que ofrecen tanto ISAPRES como FONASA. En el primer caso, sólo los planes de salud costosos contemplan cobertura para odontología $\mathrm{y}$, en el ámbito público, la baja cobertura o las listas de espera son una realidad incuestionable. Así lo constata un estudio sobre acceso a la salud y salud mental, en el que los hallazgos indican que, los pobres tienen serias dificultades para acceder a la atención de salud (médica o dental) cuando la necesitan y, cuando la obtienen, acceden con alguna demora o de manera tardía (Olavarría, 2005).

\section{Movilidad por salud hacia Tacna como respuesta de una demanda insatisfe- cha en Arica}

Los estudios revisados que vinculan movilidad transfronteriza por salud están de acuerdo en señalar que la mayoría de los viajes médicos o "turismo médico" son Sur-Sur, de corta distancia, entre países vecinos y de pacientes relativamente pobres o insatisfechos con los sistemas de salud nacionales que buscan acceder a procedimientos terapéuticos sencillos o rutinarios (Connell, 2016; Ormond \& Sulianti, 2014). Si bien existe un flujo de viajes Sur-Norte, con tratamientos o procedimientos más costosos o complejos, lo que se verifica es que hay más viajes por motivos médicos que "turismo médico" especialmente a nivel intrarregional y entre países con diferentes niveles de atención y niveles de acceso a tratamientos (Crush \& Chikanda, 2015). La dificultad es mensurar este flujo, puesto que la mayoría de las personas cruzan las fronteras en calidad de turistas y los registros de pacientes son a menudo "anecdóticos y no estadísticos" (Connell, 2016: 534). Con todo, se registra un aumento de los viajes por salud o médicos desde los años 1990 hasta la fecha, aunque claramente es difícil de cuantificar.

Tabla 1. Motivos del cruce de chilenos entre Arica y Tacna

\begin{tabular}{|l|c|c|}
\hline \multicolumn{1}{|c|}{ Motivo del cruce } & Número de personas & Porcentaje de personas \\
\hline Turismo médico & 36 & $39,60 \%$ \\
\hline Turismo general & 33 & $36,30 \%$ \\
\hline Turismo de compra & 9 & $9,90 \%$ \\
\hline Trabajo & 2 & $2,20 \%$ \\
\hline Asunto personal & 10 & $11,00 \%$ \\
\hline Comercio & 1 & $1,10 \%$ \\
\hline in between & 0 & $0,00 \%$ \\
\hline Total & $\mathbf{9 1}$ & $\mathbf{1 0 0 \%}$ \\
\hline
\end{tabular}

Fuente: Encuesta FONDECYT N 1150123. Elaboración propia, año 2017.

En este contexto se enmarca la movilidad por salud detectada en la frontera entre Arica y Tacna, donde uno de los principales motivos que declaran —en nuestra encuesta - las personas que cruzan hacia dicha ciudad es una visita al médico, a un especialista, a oftalmólogos o dentistas. Según los resultados de la encuesta aplica-

17 Ver URL: <http://radio.uchile.cl/2015/10/25/farmacia-popular-el-cuestionamiento-al-modelo-de-distribucionde-medicamentos/>. Consultado el 12 de septiembre de 2016. 
da el año 2015, el 39,6\% del total de chilenos/as que cruzaron la frontera declararon cruzar por motivos médicos, es decir, la encuesta sólo expresa el flujo AricaTacna, desconociendo los motivos del mismo, razón por la cual se realizaron posteriormente las entrevistas. Del total de encuestados que declaran motivos asociados a prácticas de salud, el 100\% son chilenos/as residentes de la ciudad de Arica y de éstos el $75 \%$ son mujeres (Tabla 1).

Tabla 2. Duración del cruce de la frontera por motivos de salud

\begin{tabular}{|c|c|c|}
\hline Número de días & $\begin{array}{c}\text { Número de personas que cruzan } \\
\text { por motivo de salud }\end{array}$ & $\begin{array}{c}\text { Total de personas que contestan } \\
\text { la encuesta }\end{array}$ \\
\hline 1 & 30 & 126 \\
\hline 2 & 2 & 33 \\
\hline 3 & 2 & 13 \\
\hline 4 & 0 & 5 \\
\hline 5 & 0 & 10 \\
\hline 6 & 0 & 12 \\
\hline 7 & 2 & 33 \\
\hline 10 & 0 & 1 \\
\hline 15 & 0 & 2 \\
\hline 30 & 0 & 3 \\
\hline 60 & 0 & 1 \\
\hline Total & $\mathbf{3 6}$ & $\mathbf{2 3 9}$ \\
\hline
\end{tabular}

Fuente: Encuesta FONDECYT Nº 1150123. Elaboración propia, año 2017.

En un trabajo anterior (Tapia Ladino, Liberona Concha \& Contreras Gatica, 2017) se sostiene que los tipos de movilidad de los residentes de Arica hacia Tacna se enmarcan en lo denominado como "prácticas socioespaciales reproductivas" o bien, acciones "que tienen como fin asegurar la reproducción social, vivienda, acceso a servicios sociales (educación, salud y saneamiento, seguridad) y recreación" (Morales, 2010: 191). Estas prácticas no ocurren desconectadas de las estructuras económicas y políticas de los países incluidos en este estudio (Chile y Perú), es decir, en su condición binacional, sino que el foco fue su expresión en el territorio donde la transfrontericidad, es decir, las conexiones e interacciones hacia uno y otro lado de la frontera es lo característico. El principal eje explicativo de estas prácticas remite a las asimetrías que se producen en las regiones fronterizas, donde las brechas de desarrollo en la frontera se traducen en diferencias cambiarias, salariales y de acceso a servicios y trabajo, dada la lógica empresarialista o mercantilista de algunas ciudades transfronterizas. Los habitantes de las regiones fronterizas son conscientes de estas brechas y usan estas diferencias a su favor, cuando los ciclos económicos los favorecen (Aponte, 2012; Jaquet, 2008).

Así, una de las principales características de las prácticas socioespaciales reproductivas, $\mathrm{y}$ en particular de la movilidad por salud, es que se realizan en tiempos cortos con cruces por un día o dos, habitualemente. Del universo encuestado, de 36 personas que declararon movilidad por motivos de salud a Tacna, treinta lo hicieron por un día mientras que dos cruzaron por dos días, otras dos personas por tres días, y dos más por una semana. Esto indica que el motivo del cruce es casi estrictamente para realizar una actividad puntual, aunque no exclusivamente, porque es frecuente que se acompañe con otras relacionadas al turismo, compras y ocio (Tabla 2). 
Entre las razones que señalan los encuestados y los entrevistados para viajar a Tacna por motivos de salud está el difícil acceso a especialistas en Arica y la demora en la atención en el sistema público chileno, en contraste con la facilidad para acceder a especialistas en Tacna y la rapidez de la atención. Tal como se sostuvo anteriormente, uno de los principales problemas del sistema de salud chileno es el bajo número de médicos respecto de la población, el desigual reparto entre el sistema público y privado y la desigual expresión a nivel regional y local. En los territorios intermedios y locales de Chile - y especialmente en las regiones extremasson escasos o insuficientes los incentivos de parte del Estado para atraer a profesionales de la salud, especialmente en algunas especialidades médicas ${ }^{18}$ que se concentran en la ciudad capital de Chile, Santiago.

Tabla 3. Especialidades médicas consultadas en Tacna

\begin{tabular}{|l|c|}
\hline \multicolumn{1}{|c|}{ Especialidad } & Número de personas que cruzan por motivo de salud \\
\hline Óptica & 12 \\
\hline Odontología & 20 \\
\hline Medicina general & 10 \\
\hline Estética & 2 \\
\hline Dermatólogo & 2 \\
\hline Neurólogo & 1 \\
\hline Naturista & 1 \\
\hline Otorrino & 1 \\
\hline Traumatólogo & 1 \\
\hline Total & $\mathbf{5 0}$ \\
\hline
\end{tabular}

Fuente: Encuesta FONDECYT N 1150123. Elaboración propia, año 2017.

En este contexto, el trabajo de campo permitió ahondar respecto al papel de la ciudad de Tacna como polo de atracción de servicios de salud, en tanto consolida una oferta médica especializada en dentistas y oftalmólogos, pero que también se ha extendido a una amplia gama de especialidades, en particular en el Hospital de la Solidaridad. La Tabla 3 muestra la variedad de especialistas a los que acuden pacientes chilenos/as en Tacna.

Uno de los entrevistados, un cirujano dentista de la ciudad de Tacna, sostuvo que los flujos médicos hacia Tacna comenzaron en los años 1970, concentrándose en algunos edificios de la Avenida Bolognesi conocida también como "calle de la salud" (Figura 2). Sin embargo, reconoce que en los últimos quince años la avenida se ha diversificado en términos de mayor oferta y calidad de servicios, generándose así una economía de escala que vincula no sólo las prácticas de salud sino también otras actividades que realizan quienes cruzan la frontera.

Uno de los informantes claves de la Municipalidad de Arica afirmó que una de las principales razones por las que los y las ariqueños/as van a Tacna es por motivos de salud en un contexto en que "el Estado chileno y también el mundo privado de la salud no logra satisfacer completamente la demanda que hay en ese ámbito, demanda que es satisfecha por el Perú [...] a través de, por ejemplo, el Hospital de la Solidaridad" (Informante, Municipalidad de Arica, 18 de julio de 2016).

18 Ver URL: <http://www.t13.cl/noticia/nacional/crece-la-campana-un-oncologo-para-punta-arenas>. Consultado el 12 de septiembre de 2016. 
El Hospital de la Solidaridad de Tacna (Figura 2) fue inaugurado el 5 de enero de 2009 y pertenece al Sistema Metropolitano de la Solidaridad SISOL creado el 2003 por el alcalde de Lima Sr. Luís Castañeda Lossio. Esta iniciativa municipal nació como una inquietud del máximo edil limeño para proveer de salud a los sectores más pobres de la ciudad de la capital. Así, a partir de un corralón en el Distrito de la Independencia en el Cono Norte de la ciudad, los antiguos autobuses abandonados en ese lugar fueron reacomodados y convertidos en consultas médicas. El modelo fue tan exitoso por la cobertura y la demanda por salud que hoy SISOL cuenta con una red de 28 hospitales distribuidos en sectores populosos de Lima y en distintas ciudades de Perú, entre ellas la de Tacna.

El Hospital de La Solidaridad o Sistema Metropolitano de la Solidaridad (SISOL) está levantado sobre un antiguo mercado de abastos a las afueras, por la ruta de ingreso a la ciudad, en la actualidad cuenta con 55 especialidades médicas y, como señaló el Director del Hospital en una entrevista con nuestro equipo, el año 2015 se hicieron 373.846 atenciones de los cuales 161.000 fueron a chilenos (Figura 1). Del total de pacientes que atiende el Hospital el porcentaje de atención a chilenos puede variar de $45 \%$ a $100 \%$ diario dependiendo de las fechas del año. Las variaciones se relacionan con las vacaciones de verano, fiestas patrias chilenas o fines de semana largos cuando los chilenos, no sólo de Arica sino de todo el norte, viajan a Tacna para ser atendidos.

Figura 2. Avenida Bolognesi, espacio representativo de la movilidad por salud

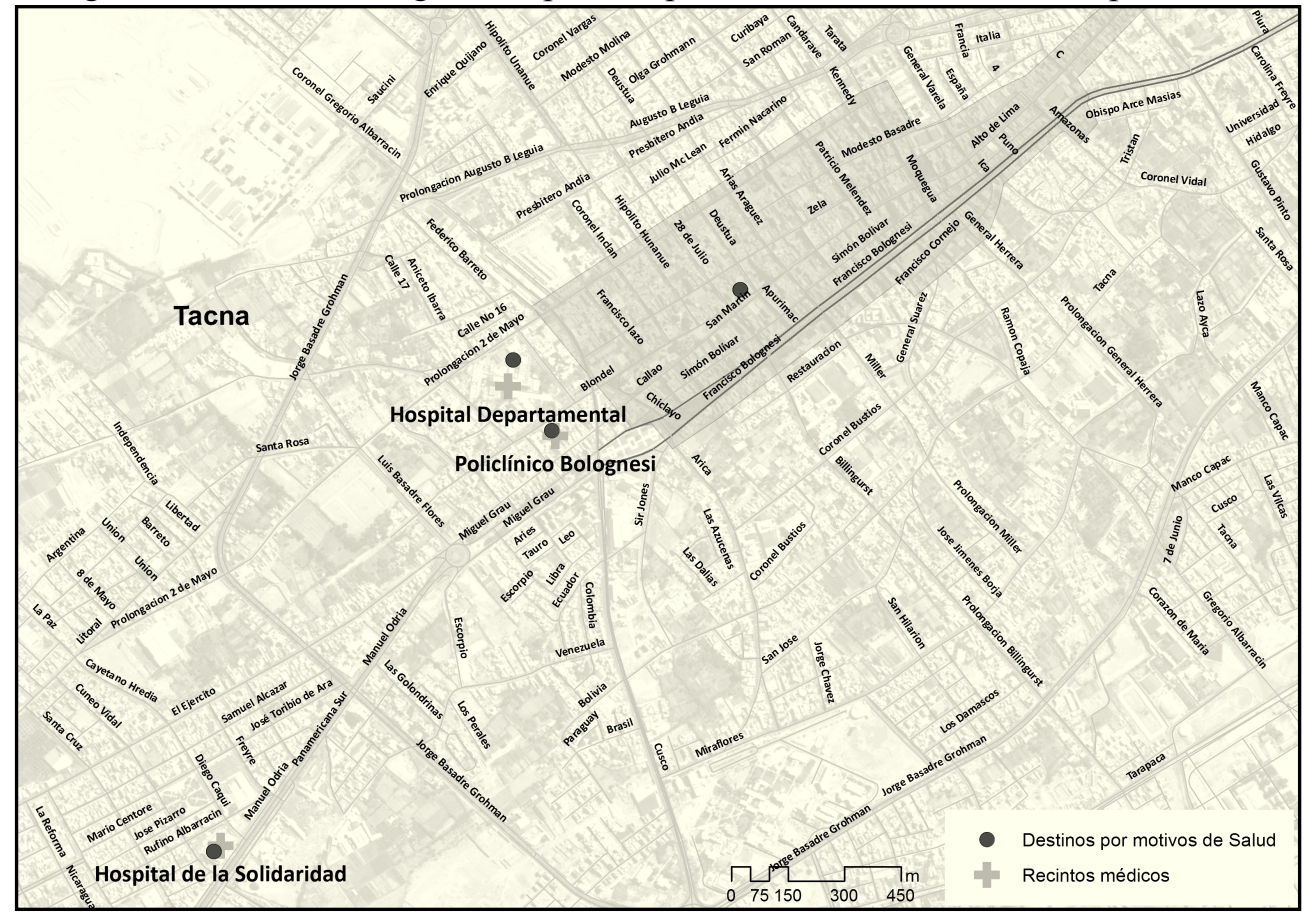

Fuente: Encuesta FONDECYT N 1150123 . Mapa elaborado por Rodrigo González, 2017 a partir de los resultados de la Encuesta, 2015. 
Solidaridad, como le llama el director del Hospital se rige por los lineamientos y mandatos de la Municipalidad de Lima, y es supervisado por el Ministerio de Salud peruano y evaluado por varias entidades fiscalizadoras. El director asegura que, en este establecimiento, la demanda chilena fue en sus inicios - año 2009- muy alta, decreciendo en algunos momentos por factores puntuales, como, por ejemplo, por despidos masivos en ciertos sectores, como la minería, una de las actividades económicas más representativas de las ciudades extractivas del norte chileno. Según datos del Hospital durante el año 2015 se hicieron 42.225 atenciones médicas a ariqueños/as (Director Hospital de la Solidaridad, Tacna, 12 de agosto de 2016).

SISOL, en palabras del director del Hospital, nació como "una alternativa de salud para el poblador peruano, como una alternativa al Sistema Público de Salud Peruano que no lograba abastecer a toda la población. Con el tiempo sus objetivos se han ido adaptando, por las demandas que vamos viendo, las necesidades que se van creando en el transcurso" (Director Hospital de la Solidaridad, Tacna, 12 de agosto de 2016). La política institucional consiste en aplicar el modelo que permite acortar los trámites burocráticos y hacer todo en un día, es decir, consulta, exámenes y revisión y en el mismo lugar sin necesidad de salir del recinto.

\section{El acceso a especialista, economía y rapidez en la atención de salud tacneña}

La situación de la salud pública en Arica es una de las más deficitarias del país, principalmente por tratarse de una zona extrema y fronteriza. El principal déficit es el de especialistas, alcanzando un 6,5 de densidad de médicos especialistas por 10.000 habitantes, lo que queda muy por debajo de países como México, España o Polonia (MINSAL, 2016: 22-23).

Tabla 4. Principales beneficios de cruzar la frontera desde Arica hacia Tacna

\begin{tabular}{|l|c|c|}
\hline \multicolumn{1}{|c|}{ Opciones } & $\begin{array}{c}\text { Personas que cruzan por } \\
\text { motivo de salud }\end{array}$ & $\begin{array}{c}\text { Total de personas } \\
\text { encuestadas }\end{array}$ \\
\hline Cercanía geográfica & 8 & 93 \\
\hline Mayor oferta de productos & 3 & 16 \\
\hline Mayor oferta laboral & 0 & 14 \\
\hline Mejor calidad de servicios educativos & 0 & 2 \\
\hline Mejor calidad de servicios sanitarios & 1 & 1 \\
\hline Más equipamientos públicos (bibliotecas, parques) & 0 & 2 \\
\hline Mejor calidad de los productos & 0 & 7 \\
\hline Ahorro de tiempo en atención & 3 & 1 \\
\hline Mejor atención (buen trato) & 0 & 19 \\
\hline Mejor sueldo & 0 & 12 \\
\hline Más lugares de entretención & 1 & 52 \\
\hline Más barato (económica) & 18 & 6 \\
\hline Mejores ofertas gastronómicas & 1 & 10 \\
\hline Otras & 1 & $\mathbf{2 3 6}$ \\
\hline Total & $\mathbf{3 6}$ & \\
\hline
\end{tabular}

Fuente: Encuesta FONDECYT N 1150123. Elaboración propia, año 2017.

Entre las razones señaladas por los entrevistados para viajar a Tacna a ver médicos está el acceso a especialistas, la rapidez en la atención y la economía, rasgos que comparativamente no encuentran en Arica (Tabla 4). El primer aspecto se co- 
rrobora en los datos arrojados por la encuesta y en las entrevistas a personas que cruzan la frontera como uno de los aspectos más valorados en la atención de salud tacneña. Como vemos, las variables tiempo y costo son las que se imponen como incentivo para viajar a Tacna, así como la opción es "más barato (económico)" con 18 puntos sobre 36 . A estos dos criterios se suma "cercanía geográfica" con 8 puntos, y, bien por detrás, "mayor oferta de productos" y "ahorro de tiempo en atención”, ambas opciones con tres puntos.

Respecto del acceso a especialistas, los entrevistados comparan la atención médica en Arica respecto de Tacna y, a partir de ese análisis, señalan las ventajas que tiene la ciudad peruana respecto de la chilena. Uno de ellos señaló:

Hace un año me dieron una hora de atención [en Arica] y todavía no me atienden, no me hacen la ficha. ;Me fui para allá [centro de salud] y me dijeron "Lo vamos a atender la próxima semana, el 24», me llaman y me dicen "iAh!, no lo vamos a atender». Después no he venido y ha pasado más de un año (1 hombre y 2 mujeres, Arica, 24 de enero de 2017).

A la dificultad para el acceso a especialistas en Arica se suma a los tiempos de espera en la atención pública. Otra entrevistada advirtió: "Acá [Arica] usted tiene que pedir hora, "Señora en un mes más, en quince días más». A veces tengo la hora en quince días, después me llaman "¿Sabe qué señora? El doctor no va a venir mañana»" (2 mujeres, Arica, 17 de enero de 2017).

En cambio, en Tacna hay una oferta amplia de especialistas, concentrada especialmente en el Hospital de la Solidaridad, lo que motiva viajes continuos para consultas y exámenes rápidos y diagnósticos oportunos. Como queda graficado en las entrevistas:

Vengo a ver distintos médicos, cardiólogos, neurólogos, es más rápido, sale más
barato, porque en un hospital de allá [Chile] pasa un año o dos años y recién tie-
nes la cita... Aquí es tan rápido todo que, por ejemplo, ahora hice todo en la ma-
ñana, vi al cardiólogo y ahora al gastroenterólogo. Tienes la biopsia tienes la en-
doscopía todo al tiro, ahora en el momento, es más rápido todo, entonces el
enfermo no muere tan rápido [risas]. Que lamentablemente allá no, fui en enero
allá [Arica], me llamaron hace poco antes de venir para darme hora recién la ho-
ra con el neurólogo. En ese tiempo podía haber fallecido (Mujer, Hospital de la
Solidaridad, 7 de octubre de 2016).

Las entrevistas permiten confirmar la idea de que la movilidad por salud es una alternativa para los y las ariqueñas/os, y chilenos del norte de Chile, especialmente por la dificultad de acceder a especialistas en Arica e Iquique, en contraste con la facilidad para acceder a la atención de especialistas en Tacna. Por tanto, la insatisfacción e incluso la frustración por no poder obtener acceso oportuno a especialistas en Chile, especialmente en el sistema público de salud motivan el viaje médico a Tacna. La disponibilidad de la atención, a lo que se suma la posibilidad de hacer los exámenes médicos en el mismo día y lugar - como ocurre en el Hospital de la Solidaridad - y el ahorro en gasto de bolsillo asociados, hacen que las personas se decidan a viajar. 
Así, en varios casos los viajes por motivos de salud constituyen una alternativa de acceso oportuno a la salud y se convierte en una práctica habitual que incluso lleva años. Una mujer ariqueña entrevistada de 58 años menciona que siempre llevó a sus hijos al pediatra en Tacna, desde los años 1980, y también para hacerse radiografías. Esta opción es principalmente de orden económico: "Es que siempre acá los médicos han sido más baratos. Eso no significa que son mejores, pero los medicamentos son más baratos" (Mujer, Hospital de la Solidaridad, 12 de agosto de 2016). Otra entrevistada señaló: "Toda la vida mi mamá me llevó [a Tacna], cuando tenía como 5 años la primera vez” (2 mujeres, Arica, 24 de enero de 2017). Por tanto, para algunos la ida al médico a Tacna es parte de sus hábitos y el viaje se constituye en una práctica cotidiana, tanto por rutina (chequeos médicos) como por atención de mayor complejidad. Así quienes cruzan por motivos de salud alternan tiempos puntuales o más días para completar sus requerimientos. Como señaló una de las entrevistadas:

Depende, por ejemplo, si me voy a hacer el chequeo completo, ahí se está todo el día. Si voy a algo puntual, de algún dolor, por ejemplo, que me duele mucho la cadera, ahi el medio día. Lo atiende el médico, la manda a hacer la radiografía, uno retorna al tiro o máximo a las tres de la tarde uno va a ver los resultados y después uno queda libre (2 mujeres, Arica, 17 de enero de 2017).

El acceso oportuno a especialistas y la rapidez en la atención en Tacna deja en evidencia las carencias y lentitud del sistema público de salud chileno, lo que se configura como uno los principales incentivos para el cruce de la frontera. De modo que la esperanza de detectar una enfermedad en una etapa temprana y prevenir su progresión hace de la atención y del servicio un atractivo para pacientes molestos con los tiempos de espera del sistema sanitario chileno. Como lo representa gráficamente uno de los entrevistados: "Yo voy en realidad por la prontitud, porque como yo ya estoy en... como en la recta final de mi vida, entonces lo quiero todo, yo lo quiero todo para ayer, digamos" (1 hombre y 2 mujeres, Arica 24 de enero de 2017).

Así la oferta médica tacneña se constituye en torno a una característica diferenciadora respecto del sistema chileno de salud, que es más engorroso y lento, mientras que en Tacna y en especial en el Hospital de la Solidaridad "es todo de una inmediatez" (Informante clave, Municipalidad, Arica, 18 de julio de 2016). La atención rápida permite que las personas que combinan atención médica con ocio organicen el viaje para ser atendidos y para disfrutar de los atractivos de Tacna. Como señala una de las entrevistadas, que se toma tres días cada vez que va a Tacna, al llegar:

Vamos a cambiar [moneda] al tiro (sic) los soles. Nunca vamos ese día de llegar al médico, sino que, al otro día, entonces de ahi en la tarde nos dedicamos a pasear [...] Mire, ellos funcionan de las 06:30 de la mañana que ya está abierto, pero para nosotros son las 08:00. Nosotros tenemos la diferencia de dos horas, entonces estamos ahi ya temprano (2 mujeres, Arica, 24 de enero de 2017).

El polo de atracción no es exclusivamente el Hospital de la Solidaridad, sino toda la oferta oftalmológica y dental en el centro de la ciudad. Esto que se aprecia al 
caminar por la Avenida Bolognesi que está repleta de ópticas y consultas dentales. De la misma manera que el acceso a especialistas es rápido, la hechura de anteojos o atenciones dentales puntuales también se pueden hacer en el mismo día. Son igualmente atractivos los tratamientos ortodóncicos, que toman más tiempo y que implican crucen mensuales a Tacna.

Al rápido acceso a los especialistas se suma la economía de la consulta, los medicamentos y las recetas. El costo en especialidades médicas es otro aspecto que destacan quienes cruzan a Tacna para atenderse, como afirma otra de las entrevistadas: "Desde cuándo empezamos a venir acá a los médicos... más de unos diez años ya, más, más. A ver, mi hijo tiene unos 33; yo creo que antes de ese tiempo, sobre todo cuando era [...] La cardiología siempre ha sido más barato, y pediatría también” (Mujer, Tacna, 12 de agosto de 2016).

Así que son tres los motivos que más valoran los ariqueños para cruzar la frontera y atenderse en Tacna - que se comprenden a la luz de la comparación que ellos hacen del sistema de salud público chileno e incluso privado-: el acceso a especialistas de manera inmediata, la realización de exámenes y análisis de los mismos por parte de los médicos en un mismo día, a lo que se suma los costos de la/s consulta/s y la realización de los exámenes. Si a ello agregamos la proximidad entre Arica y Tacna y las demás opciones que tiene la ciudad, todo hace que el viaje no sea sólo por motivos de salud y se combine salud, compras y ocio.

\section{Calidad y confianza de la atención médica tacneña en un contexto separa- dor de la frontera}

Las apreciaciones sobre la calidad de los servicios son dispares, para algunos la atención médica y el trato son mejores en Tacna, sin embargo, al consultar sobre las intervenciones de mayor complejidad, no hay consenso en la respuesta. Respecto de lo primero uno los aspectos más valorados de la atención de salud es el trato de los médicos tacneños a diferencia de los chilenos. Como señala uno de los entrevistados:

Acá [Arica] hay que estar esperando meses para que nos atiendan y cuando nos atienden prácticamente acá los médicos en Chile se creen dioses, entonces si usted les hace una pregunta «Yo soy el doctor', pero soy yo la enferma, yo quiero saber, ellos no le enseñan. Allá [Tacna] el médico le enseña con peras y manzanas a usted le dice "Pero usted tiene este problema, por esto, por este otro, por este otro, que podemos hacer esto, y esto y esto otro». Eso acá los médicos no lo hacen (2 mujeres, Arica, 24 de enero de 2017).

Uno de los entrevistados señaló que por un problema de audición viajó al Hospital de la Solidaridad (Figura 2) para atenderse con un otorrino durante la consulta valoró la atención y el tiempo dedicado para comprender qué le ocurría:

[...] yo le pregunté a la doctora "¿Doctora por qué pasa eso de la audición que uno de repente uno la pierde?, empieza un ruido por acá de mar». "A todos les pasa» me dijo, "pueden ser jóvenes, adultos mayores, pero es una inflamación que se produce dentro del oido y usted viene inmediatamente y a la semana se le quita. 
Si usted se queda con ese dolor no se quita, se queda permanente». Y «¿Cuánto se va a demorar?». "Siete días», me dijo. Me dio tres medicamentos y a los cinco días no tenía nada (1 hombre y 2 mujeres, 24 de enero de 2017).

Al buen trato en la atención médica se suma el tiempo de dedicación en la consulta. Como señaló otro entrevistado: "la gran diferencia, y soy tajante, es que allá [Tacna] tienen tiempo para atenderte y acá [Arica] no" (Hombre, Chacalluta, 2016).

Otro elemento que se enmarca en la calidad del servicio se relaciona con el equipamiento médico para realizar exámenes, así lo señaló una de las entrevistadas: "Me trato el corazón porque tienen mejores máquinas que acá, porque yo tengo la mitad del corazón más grande" (Mujer, Chacalluta, 2016). La comparación se hace en referencia a lo existente en Arica, como señala otro entrevistado:

Hay bastantes especialidades y ¿sabes que me gusta a mí... el instrumental. Por ejemplo, para hacer esto, estas cosas así... encefalogramas con maquinarias, estamos comparando con Arica no más, con máquinas mucho más nuevas, como con nuevas tecnologías" (1 hombre, 2 mujeres, Arica 24 de enero de 2017).

Sin embargo, entre los entrevistados no hay consenso en torno a la confianza en el sistema de salud tacneño para intervenciones de mayor complejidad, como una operación. Lo que se aprecia es que en varios casos los usuarios de salud ariqueños alternan la atención en Tacna con la atención privada o pública en Chile. Por ejemplo, una de las entrevistadas cuenta que su familia prefiere la atención privada en Arica porque el sistema público es muy lento, por lo que se le pregunta si combina los sistemas de salud de ambos países a lo cual responde: "Ahora fue más que nada por urgencia, porque necesitaba hacerlo rápido y en Arica no teníamos hora. Aqui [Tacna] los exámenes, particular, me salió 40 mil pesos, que allá en Arica me salen 80" (Mujer, Hospital de la Solidaridad, 12 de agosto de 2016).

Un hombre ariqueño entrevistado, de 62 años, refuerza esto último: él sólo ha ido a hacerse un electrocardiograma y señala: "Una segunda opinión me la hice en Arica, pero yo no me quedo con lo que dicen en Tacna [...] por un tema de desconfianza" (Hombre, Chacalluta, 2016). Al parecer, una mala experiencia o una desconfianza inicial provocan el rechazo hacia este tipo de servicio. Un hombre ariqueño de 35 años cuenta que tuvo sólo una experiencia con un dentista, al consultarle sobre cómo sintió que fue el tratamiento responde: "A la ligera...". Y al preguntarle por las diferencias entre médicos de allá (Tacna) y de acá (Arica), declara: "acá son mejores, pero son más caros, valen el doble o el triple" (Hombre, Chacalluta, 2016).

Sin embargo, otro entrevistado manifestó mayor confianza en el servicio que ofrece el Hospital de la Solidaridad: "Es confiable, por lo menos este lugar. Como te dije, pienso, no lo tengo claro que tiene que haber un tipo de fiscalización estatal, como es del gobierno. No así las clínicas, que son tierra de nadie" (Hombre, Hospital de la Solidaridad, 7 de octubre de 2016).

La desconfianza ante procedimientos de mayor complejidad se relaciona con la dificultad de hacer un reclamo posterior y con el temor a lo desconocido. El hecho de cruzar como turistas, atenderse como tales y no contar con seguros hace que las personas lo piensen dos veces en una intervención más compleja. Como señaló una 
entrevistada: "Yo pienso si por A, B y C algo pasa, yo no me puedo quejar, ¿me entiende? o sea yo no puedo. En cambio, en Chile usted puede seguir un conducto regular, que le hagan su operación como debe ser, ¿me entiende?" (1 hombre, 2 mujeres, Arica, 24 de enero 2017). Sin embargo, los entrevistados son conscientes de la existencia de una oferta en torno a tratamientos que requieren intervención quirúrgica y de la existencia de una serie de servicios asociados, pero no todos los utilizan.

Sin embargo, cada vez está más extendida la oferta de operaciones rutinarias, desde operación para cataratas o desprendimiento de retina hasta operaciones estéticas como liposucción o rinoplastia, cuyo público objetivo es en su mayoría chileno. Sin embargo, no todas las personas que acceden a ellas - especialmente a cirugías estéticas - declaran estas experiencias puesto que prefieren la confidencialidad, aunque los anuncios en las calles y en la prensa ariqueña e incluso iquiqueña revela un creciente mercado al respecto.

Al preguntar si los conflictos fronterizos entre Chile y Perú, como por ejemplo el fallo de La Haya (27 de enero de 2014), afectan a la circulación entre Arica y Tacna, la mayoría de los encuestados declaró que no. En particular, el director del Hospital de la Solidaridad señaló al respecto: "No, es problema de la historia entre Chile y Perú, sin embargo, Arica y Tacna siempre se mantienen cuasi al margen de algunos problemas. Nos siguen visitando, nosotros seguimos visitándolos" (Directo Hospital de la Solidaridad, Tacna, 12 de agosto 2016). De manera similar un dentista entrevistado afirmó:

Yo creo que esos conflictos diplomáticos, limitrofes que tenemos con Chile, La Haya, todas esas cuestiones se han mantenido al margen de la cuestión comercial y profesional entre Tacna y Arica. Acá en Tacna, nosotros los tacneños no nos interesamos mucho por eso, no es una cosa que gravite mucho en nuestra vida, que le afecte o que diga: ";Oh!, no voy a atender porque La Haya», no. La gente sigue trabajando... un poco al margen, la gente quiere seguir vendiendo sus cosas, quiere que la gente chilena venga porque es una realidad: dependemos mucho de lo que viene, de la gente de Chile (Dentista, Tacna, 21 de julio de 2016).

En general los entrevistados/as señalan que el impacto de las relaciones diplomáticas o los litigios entre Chile y Perú no afectan a la interacción entre Arica y Tacna. Los residentes de Arica siguen cruzando la frontera a pesar de la tensión diplomática que se ha producido en algunos momentos, de hecho, cuando más se ha visto afectada ha sido con los paros de funcionarios públicos chilenos o paro de camioneros que afectan directamente la circulación en la frontera. En esos casos, se aprecia una merma en el flujo, mas no la detención; sin embargo, son estas las coyunturas en las que ariqueños y tacneños sufren millonarias pérdidas por la disminución del comercio y el consumo especialmente de Tacna ${ }^{19}$. Esto no significa que la frontera pierda el carácter separador o desaparezca el contenido nacionalista de la misma, sino que hay un reconocimiento de la mutua dependencia entre ambas ciudades. La mayoría de los entrevistados estuvo de acuerdo en señalar que Arica y

19 Ver URL: <http://www.emol.com/noticias/Nacional/2016/06/22/808992/Paro-de-camioneros-en-Arica-dejaperdidas-por-US-5-millones.html>. Consultado el 12 de enero de 2017. 
Tacna se necesitan y que en esa relación los conflictos bilaterales son incluso perjudiciales para la vida de los habitantes de la frontera. Como señaló un entrevistado: "Yo tengo la sensación de que los conflictos están en Lima y en Santiago" (1 hombre y 2 mujeres, 25 de enero, 2017).

\section{Conclusiones}

Los estudios que vinculan frontera y salud advierten sobre el aumento de los viajes por motivos médicos o lo que hemos llamado "movilidad por salud" en distintas partes del mundo y particularmente en las regiones fronterizas. Las asimetrías y las desigualdades que producen las fronteras, sumado a las inequidades de los sistemas nacionales de salud animan a pacientes pobres o clases medias insatisfechas a cruzarlas para responder a una necesidad sanitaria, más que por un deseo o capricho. En este sentido, lo que ocurre en la frontera entre Chile y Perú, cuya expresión territorial se manifiesta en los cruces entre Arica y Tacna, es parte de la búsqueda de las personas por acceder a un servicio de salud rápido, especializado, oportuno, económico y con buen trato, de manera similar a lo que ocurre en otras partes del mundo (Pan \& Chen, 2014; Ormond \& Sulianti, 2014; Peiter, 2007; VindrolaPadros, 2015; Parella, 2014). Por tanto, este trabajo ha demostrado empíricamente que se trata de un movimiento de población, de corta distancia y poco tiempo, que se traduce en un tipo de movilidad característico de una región fronteriza. La movilidad por salud si bien se diferencia de las movilidades de larga distancia analizadas por Tarrius, rompen igualmente con el paradigma de la sedentarización, ya que manifiestan la capacidad de traspasar una frontera nacional, con el control burocrático fronterizo - hoy más expedito - , para resolver un problema puntual de salud $\mathrm{y}$, por lo demás, dan cuenta de la continuidad territorial y complementariedad social y económica de la región fronteriza.

Así, la noción de movilidad por salud, derivada del análisis de la encuesta aplicada el 2015, complementado con el análisis de las entrevistas semiestructuradas a informantes claves y cruzadores, permitió comprender las razones de los cruces y comprender los déficits del sistema de salud chileno, especialmente de Arica. La privatización y mercantilización del Sistema de Salud sumado a la dificultad de atraer y retener médicos especialistas en el norte de Chile ha motivado que sus habitantes busquen satisfacer la demanda de servicios sanitarios al otro lado de la frontera. Estos cruces se constituyen en una dinámica transfronteriza que discute el contenido supuestamente local y nacional del sistema de salud y la resolución de las demandas sanitarias en el territorio al que pertenecen los pacientes. Demostrándose así que las regiones fronterizas son dinámicas en su desarrollo, porque están afectadas por distintas fuerzas a nivel global, nacional y local, y la existencia de la frontera des/incentiva el cruce por distintos motivos, dando lugar a nuevas modalidades más allá del carácter separador del límite. Así, la movilidad por salud de ariqueños a Tacna no sólo da cuenta del déficit de la atención sanitaria en Chile — que es además crítico en las regiones extremas-, sino que pone de relieve dos aspectos que resultan llamativos: por una parte, discute la idea que está en la base de la explicación sobre el aumento de la migración reciente de sudamericanos y caribeños a Chile, como un lugar con mejores condiciones económicas, sociales y políticas; y 
por otra, da cuenta de los procesos de mercantilización de la salud y de la expresión transfronteriza de los servicios de salud entre estas ciudades fronterizas.

Estos resultados permiten comenzar a responder las preguntas iniciales, ya que existe una demanda de atención sanitaria insatisfecha en Arica que, gracias a la cercanía y servicio tacneño, es satisfecha en la ciudad peruana. Así, el cruce fronterizo se presenta como una oportunidad de acceder a un servicio de salud de forma inmediata y asequible. La dimensión económica de las prácticas espaciales realizadas por salud resulta significativa, en términos de las restricciones que impone el sistema, específicamente en la atención odontológica. De la misma forma el gasto de bolsillo se ve favorecido por los bajos valores de la atención sanitaria, especialmente en lo referente al pago de especialistas, 1 cuyo ahorro puede ser de hasta 10 veces respecto de lo que cuesta en Chile. Estas ventajas incentivan viajes no sólo de ariqueños sino de población proveniente de todo el norte de Chile, especialmente de Iquique, Antofagasta y Calama.

Por otra parte, las respuestas dispares sobre la calidad de los servicios es entendible en tanto se basan en percepciones subjetivas de las y los entrevistados/as, las que ayudan a entender que esta práctica transfronteriza responde a diferentes patrones, entre éstos: la costumbre del cruce para algunos ariqueños/as, una alternativa transitoria, una urgencia médica dental o bien, oftalmológica, o también —como lo vimos en la literatura revisada - un recurso o capital de movilidad, dada la disparidad en el acceso a la salud en espacios de proximidad. Por esto aparece relacionada a otras actividades turísticas y de ocio que, en algunos casos se pueden asociar a una práctica social de consumo transfronterizo, propio de otras regiones fronterizas, que mencionamos antes. En este punto se abre un aspecto a seguir explorando, en tanto la movilidad por salud es una opción que no siempre es considerada la mejor, pero es una alternativa frente al déficit del sistema de salud chileno. Por tanto, esta investigación abre la puerta a nuevas reflexiones sobre la complementariedad social y cultural del territorio circulatorio que emerge entre Tacna y Arica.

\section{Bibliografía}

Abel, L. \& Caggiano, S. (2006) "Enfermedades de Estado(s). Los inmigrantes y el acceso a la salud en una provincia de frontera", en E. Jelin \& A. Grimson (eds.) Salud y migración regional: Ciudadanía, discriminación y comunicación intercultural. Buenos Aires: IDES, 57-90.

Aguilar, Á. \& Costilla, M. (2009) “Miradas sobre fronteras en un espacio local”. Frontera Norte, vol. 21, núm. 41, 53-75.

Amilhat Szary, A.-L. \& Rouvière, L. (2011) "Des dynamiques transfrontalières au bilan d'aménagement du territoire: Innovations et blocages dans les Andes centrales (ChiliPérou-Bolivie)". Revue Mosella, vol. 32, núm. especial "Frontières et Aménagement", 181-196.

Aponte, J. (2012) "Comercio y ocio en la transformación del espacio urbano fronterizo de Leiticia y Tabatinga", en C. Zárate et al.: Espacios urbanos y sociedades transfronterizas en la Amazonía. Leticia: Universidad Nacional de Colombia, 205-235. 
Aravena, P. \& Inostroza, M. (2015) “¿Salud Pública o Privada? Los factores más importantes al evaluar el sistema de salud en Chile”. Revista Médica de Chile, núm. 143, 244251.

Banerjee, P. \& Chen, X. (2013) "Living in in-between spaces: A structure-agency analysis of the India-China and India-Bangladesh borderlands". Cities, vol. 34, núm. 1, 18-29.

Benedetti, A. (2011) "Frontera y movilidad. Aproximación al caso argentino-boliviano". Revista do Centro de Educacao e Letras, vol. 13, núm. 1, 55-80.

Brambilla, C. (2015) "Exploring the critical potential of the borderscapes concept". Geopolitics, vol. 20, núm.1, 14-34.

Caggiano, S. (2007) "Madres en la frontera: género, nación y los peligros de la reproducción”. Íconos. Revista de Ciencias Sociales, núm. 27, 93-106.

Castillo, M. \& Nájera, J. (2014) “México como país de origen, tránsito y destino de migrantes, una revisión a partir de la emif norte y la emif sur, en Consejo Nacional de Población: 20 años de la Encuesta sobre Migración en la Frontera Norte de México, 17-35.

Cerruti, M. (2006) "Problemas de salud, utilización de servicios y conductas preventivas de los migrantes limítrofes en la Argentina", en E. Jelin \& A. Grimson (eds.) Salud y migración regional: Ciudadanía, discriminación y comunicación intercultural. Buenos Aires: IDES, 15-32.

Cid, C. \& Prieto, L. (2011) "Inequidad en el financiamiento de la salud y su impacto en la distribución del ingreso en Chile". Ponencia en las XXXI Jornadas de Economía de la Salud, Palmas de Mallorca, España.

Coelho, J. (2012) "Limites e paradoxos da cidadania no território fronteiriço: o atendimento dos brasiguaios no sistema público de saúde em Foz do Iguaçu (Brasil)”. Geopolítica(s), vol. 3, núm. 2, 185-205.

Connell, J. (2015) "From medical tourism to transnational health care? An epilogue for the future". Social Science \& Medicine, núm. 124, 398-401.

Connell, J. (2016) "Reducing the scale? From global images to border crossings in medical tourism". Global Networks, vol. 16, núm. 4, 531-550.

Courtis, C.; Liguori, G. \& Cerrutti, M. (2010) Migración y salud en zonas fronterizas: el Estado Plurinacional de Bolivia y la Argentina. Santiago de Chile: CELADE.

Crush, J. \& Chikanda, A. (2015) "South-South medical tourism and the quest for health in Southern Africa”. Social Science \& Medicine, núm. 124, 313-320.

Dal Prá, K. R.; Mendes, J. M. R. \& Mioto, R. C. T. (2007) "O desafio da integração social no MERCOSUL: uma discussão sobre a cidadania eo direito à saúde”. Cadernos de Saúde Pública, vol. 23, supl. 2, S164-S173.

Eilenberg, M. \& Wadley, R. L. (2009) "Borderland livelihood strategies: The socioeconomic significance of ethnicity in cross-border labour migration, West Kalimantan, Indonesia". Asia Pacific Viewpoint, vol. 50, núm. 1, 58-73.

Gárate, J. (2016) "Flujos de visitantes y turistas 2011-2015". Ponencia en el I Congreso de Desarrollo Fronterizo Arica-Tacna: ¿la frontera como oportunidad para el desarrollo?, Universidad Arturo Prat, Arica.

Glinos, I. A. et al. (2010) "A typology of cross-border patient mobility". Health \& Place, vol. 16, núm. $6,1145-1155$.

González, S. (2004) "La tercería boliviana y el problema de la mediterraneidad". Revista Fuerzas Armadas y Sociedad, año 18, núm. 1-2, 23-36. 
González, S. (2007) "La emergencia de la triple-frontera andina: Perú, Bolivia y Chile", en S. González et al.: Cátedras de Integración Andrés Bello (Serie Integración social y fronteras). Bogotá: Convenio Andrés Bello, 15-54.

González, S. (2011) "El Norte Grande de Chile: La definición histórica de sus límites, zonas y líneas de frontera, y la importancia de las ciudades como geosímbolos fronterizos". Revista Historia Social y de las Mentalidades, vol. 13, núm. 2, 9-42.

Goyenechea, M. \& Sinclaire, D. (2013) "La privatización de la salud en Chile". Políticas Públicas, núm. 6, 35-51.

Hui, E. C. M. et al. (2011) "Integrations, identity and conflicts: A cross-border perspective on residential relocation of Hong Kong citizens to Mainland China". Habitat International, vol. 35, núm. 1, 74-83.

Jaquet, H. (2008) "Más allá de la frontera, las fronteras: una aproximación socioespacial a las situaciones fronterizas de Misiones, Argentina", en H. Dilla Alfonso (ed.) Ciudades en la frontera. Aproximaciones críticas a los complejos urbanos transfronterizos. Santo Domingo, 33-66.

Jelin, E. \& Grimson, A. (2005) Salud y migración regional: ciudadanía, discriminación y comunicación intercultural. Buenos Aires: IDES.

Konrad, V. \& Nicol, H. N. (2011) "Border Culture, the Boundary Between Canada and the United States of America, and the Advancement of Borderlands Theory". Geopolitics, vol. 16, núm. 1, 70-90.

Legido-Quigley, H. et al. (2012) "Analysing arrangements for cross-border mobility of patients in the European Union: A proposal for a framework". Health Policy, núm. 108, 27-36.

Liberona, N. (2012) "De la alterización a la discriminación en un sistema público de salud en crisis: conflictos interétnicos a propósito de la inmigración sudamericana en Chile". Revista de Ciencias Sociales, núm. 28, 1-38.

Marcu, S. (2016) "Learning Mobility Challenging Borders: Cross-border Experiences of eastern European Immigrants in Spain”. Mobilities, vol. 11, núm. 3, 343-361.

MINSAL (2016) "Informe sobre brechas de personal de Salud por servicio de salud" [URL: $<$ http://web.minsal.cl/wp-content/uploads/2015/08/Informe-Brechas-RHS-en-SectorP\%C3\%BAblico_Marzo2016.pdf $>$. Consultado el 20 mayo 2017].

Mombello, L. (2006) "El acceso a la salud de los inmigrantes limítrofes en el Alto Valle de Río Negro y Neuquén”, en E. Jelin \& A. Grimson (eds.) Salud y migración regional: Ciudadanía, discriminación y comunicación intercultural. Buenos Aires: IDES, 91-102.

Morales, A. (2010) "Desentrañando fronteras y sus movimientos transnacionales entre pequeños Estados. Una aproximación desde la frontera Nicaragua-Costa Rica”, en M. E. Anguiano \& A. M. López (eds.) Migraciones y frontera. Nuevos contornos para la movilidad internacional. Barcelona: Icaria, 185-224.

Newman, D. (2015) "Revisiting good fences and neighbours in a postmodern world after twenty years: theoretical reflections on the state of contemporary border studies". Nordia Geographical Publications, vol. 44, núm. 4, 13-19.

Olavarría, M. (2005) “Acceso a la salud en Chile”. Acta Bioethica, año XI, 1-47.

Ormond, M. (2015) "Solidarity by demand? Exit and voice in international medical travel The case of Indonesia". Social Science \& Medicine, núm. 124, 305-312.

Ormond, M. \& Sulianti, D. (2014) "More than medical tourism: lessons from Indonesia and Malaysia on South-South intra-regional medical travel". Current Issues in Tourism, vol. 20, núm. 1, 94-110. 
Pan, T.-J. \& Chen, W.-C. (2014) “Chinese medical tourists - Their perceptions of Taiwan”. Tourism Management, vol. 44, núm. 1, 108-112.

Parella, S. (2014) "Una exploración de las prácticas transfronterizas en la zona urbana Caléxico (Estados Unidos)-Mexicali (México)” en M. Tapia Ladino \& A. González Gil (comps.) Regiones fronterizas, migración y los desafios para los Estados nacionales latinoamericanos. Santiago de Chile: RIL Editores, 41-69.

Rodríguez Elizondo, J. (2014) Historia de dos demandas: Perú y Bolivia contra Chile. Santiago de Chile: El Mercurio.

Rojas, M. et al. (2008) “Trabajo y migración femenina en la frontera sur de México”, en G. Herrera \& J. Ramírez (eds.) América Latina migrante: Estado, familia, identidades. Quito: FLACSO/Ministerio de Cultura, 141-158.

Sheller, M. \& Urry, J. (2006) "The new mobilities paradigm". Environment and Planning $A$, vol. 38, núm. 2, 207-226.

Steiman, R. (2012) "Zona de fronteira e cidades gemeas: Uma tipologia das interacoes transfronteiricas”, en C. E. Zárate (ed.) Espacios urbanos y sociedades transfronterizas en la Amazonía. Leticia: Universidad Nacional de Colombia, 154-166.

Tapia Ladino, M.; Liberona Concha, N. \& Contreras Gatica, Y. (2017) "El surgimiento de un territorio circulatorio en la frontera chileno-peruana: estudio de las prácticas socioespaciales fronterizas". Revista de Geografía Norte Grande, núm. 66, 117-141

Tarrius, A. (2000) "Leer, describir, interpretar las circulaciones migratorias: conveniencia de la noción de «territorio circulatorio». Los nuevos hábitos de la identidad". Relaciones, vol. 21, núm. 83, 39-66.

Tarrius, A. (2007) La mundialización por abajo. El capitalismo nómada en el arco mediterráneo. Barcelona: Hacer Editorial.

Tarrius, A. (2010) “Territoires circulatoires et étapes urbaines des transmigrant(e)s". Regards croisées sur l'économie, vol. 2, núm. 8, 63-70.

Trillo, J. M. \& Lois, R. C. (2011) "La frontera como motivo de atracción: una breve mirada a las relaciones Galicia-Região Norte". Geopolitica(s). Revista de estudios sobre espacio y poder, vol. 2, núm. 1, 109-134.

Tripathi, D. (2015) "Interrogating Linkages Between Borders, Regions, and Border Studies". Journal of Borderlands Studies, vol. 30, núm. 2, 189-20.

Valdivieso, V. \& Montero, J. (2010) "El plan AUGE: 2005 al 2009”. Revista médica de Chile, núm. 138, 1040-1046.

Vindrola-Padros, C. (2015) “A Cautionary Tale: The 'New'Medical Tourism Industry in Argentina”. Somatechnics, vol. 5, núm. 1, 69-87.

Waldman, T. C. (2011) "Movimentos migratórios sob a perspectiva do direito à saúde: imigrantes bolivianas em São Paulo". Revista de Direito Sanitário, núm. 12, 90-114.

Zapata-Barrero, R. \& Ferrer-Gallardo, X. (2012) "Las fronteras en la época de la movilidad”, en R. Zapata-Barrero \& X. Ferrer-Gallardo (eds.) Fronteras en movimiento. Migraciones hacia la Unión Europea en el contexto mediterráneo. Barcelona: Edicions Bellaterra, 11-56. 